\title{
Is Circulating Osteocalcin Related to Adipokines and Overweight/Obesity in Children and Adolescents?
}

\author{
Authors \\ Affiliations \\ Key words \\ - osteocalcin \\ - children \\ overweight \\ - adipokines \\ - leptin \\ $\checkmark$ adiponectin
}

\author{
G. M. C. Flemming ${ }^{1}$, S. Petzold ${ }^{1}$, C. Meigen ${ }^{1}$, A. Körner ${ }^{2}$, W. Kiess ${ }^{1}$, J. Kratzsch ${ }^{3}$
}

${ }^{1}$ Department of Women and Child Health, University of Leipzig, Leipzig, Germany IFB AdiposityDiseases, University of Leipzig, Leipzig, Germany

${ }^{3}$ Institute of Laboratory Medicine, Clinical Chemistry and Molecular Diagnostics, University of Leipzig, Leipzig, Germany

received $\quad 06.10 .2011$

first decision 10.02 .2012

accepted $\quad 13.02 .2012$

\section{Bibliography}

Dol http://dx.doi.org/

10.1055/s-0032-1306287

Published online:

March 22, 2012

Exp Clin Endocrinol Diabetes

2012; 120: 383-387

(c) J. A. Barth Verlag in Georg Thieme Verlag KG Stuttgart · New York ISSN 0947-7349

\section{Correspondence}

\section{G. M. C. Flemming}

Department of Women and

Child Health

University of Leipzig

Liebigstraße 21a

04103 Leipzig

Germany

Tel.: +49/341/9726 822

Fax: $+49 / 341 / 9726279$

gunter.flemming@medizin.

uni-leipzig.de

\section{Abstract \\ $\nabla$}

Background: Osteocalcin (OC) has recently been described to be involved in the regulation of glucose and energy metabolism. We aimed to evaluate whether or not OC serum levels were related to parameters of overweight and serum adipokine levels of healthy children and adolescents in dependence on gender and pubertal stage.

Methods: In a cross sectional study (Leipzig Schoolchildren Project) 497 healthy, caucasian children and adolescents of all pubertal stages were included. We measured anthropometric data height, weight, fat mass, waist-to-hip ratio, pubertal development and performed biochemical analyses of osteocalcin, leptin, adiponectin and resistin serum levels by immunoassay.

\section{Introduction}

\section{$\nabla$}

Osteocalcin (OC), also known as bone Gla protein (BGP), is one of the very few osteoblast-specific proteins. It is synthesized by mature osteoblasts, odontoblasts and hypertrophic chondrocytes during the process of bone formation. However there was no clear correlation of OC serum concentration to bone mass. OC has several features of a hormone: it is synthesized as a prepromolecule, it is a cell-specific molecule, it is secreted into the circulation, but a receptor has not yet been identified. Posttranslationally, OC undergoes a vitamin $\mathrm{K}$ dependent carboxylation. In healthy adults a relatively large fraction (20$30 \%$ ) of circulating OC is uncarboxylated, and this fraction in children is even larger (up to 60\%) [1]. In mice it was shown, that the carboxylated part has a higher affinity to hydroxyapatite of the bone, whereas the uncarboxylated fraction of OC is possibly responsible for putative effects on glucose homeostasis [2].
Results: OC serum levels were associated with pubertal development achieving peak values at Tanner stage 3. There was no significant association of OC serum levels with overweight and obesity as measured by BMI and WHR. In addition, OC demonstrated no significant association with serum levels of leptin and adiponectin but a negative association with resistin in both genders independent of pubertal stages $(r=-0.329$, $\mathrm{p}<0.0001$ ).

Conclusion: We conclude that there is no major relationship between $\mathrm{OC}$ and metabolism, but we can not exclude minor relations between OC and metabolism. The negative relationship with serum resistin levels might rather point to a link between $\mathrm{OC}$ and inflammatory states.

OC deficient mice develop a phenotype marked by higher bone mass and improved quality of bone function, revealing $\mathrm{OC}$ as a determinant for bone formation [3]. Interestingly, these OC deficient mice had higher blood glucose levels, lower insulin levels and they were obese [2]. In normal mice continuous OC administration affected insulin secretion, insulin sensitivity and fat mass [4]. OC acts directly on pancreatic beta cells in culture and in vivo, leading to increased beta cell mass and increased insulin secretion, respectively OC can ameliorate the severity of obesity and type 2 diabetes in mice. In patients with type 2 diabetes several studies showed that OC serum levels were reduced. Children suffering from type 1 diabetes have been reported to have significantly lower OC levels than healthy control subjects at the same pubertal stage [5]. Hence, it appears from these studies that $\mathrm{OC}$ is decreased in states of reduced insulin secretion and resulting in hyperglycemia. On the other hand, in a recent study it was shown that OC levels were 
lower in obese children and that they were related to insulin resistance (IR) and leptin serum concentrations. It was therefore hypothesized that OC could represent a new link between obesity and IR [6]. Accordingly, our studies are aimed to evaluate whether or not OC serum levels are related to parameters of overweight and serum adipokine levels in a cross sectional study in children and adolescents.

\section{Subjects and Methods \\ $\nabla$}

\section{Study population}

The study population consisted of 497 healthy Caucasian children and adolescents from the Leipzig Schoolchildren Project [7]. Informed consent was obtained from parents and subjects 12 years of age or older. Pubertal stages were determined according to Marshall and Tanner (as described in 1969 and 1970). Subjects were selected and grouped according to gender and pubertal stage; 45-54 individuals for each pubertal stage in each sex (Tanner stages, TS 1-5). We grouped patients according to TS in early pubertal (TS 1 and 2), mid pubertal (TS 3) and late pubertal (TS 4 and 5) groups. Clinical examination and blood withdrawing was performed between 0800 and $1100 \mathrm{~h}$. The study protocol was approved by the Ethical Committee of the Medical Faculty of the University of Leipzig, Germany, Numbers 781 and 782.

\section{Measurement of anthropometric parameters}

Height and weight were determined using precision stadiometers and scales to the nearest of $0.1 \mathrm{~cm}$ and $0.1 \mathrm{~kg}$, respectively. For standardization of height and weight, reference percentiles for central Germany were applied [8]. The body mass index (BMI) was standardized referring to national reference data [9]. The waist to hip ratio (WHR) was calculated by measuring the waist at the smallest circumference between hip and chest, and hip circumference at the widest using a nonstretchable metric band.

Underweight, normal weight and overweight were defined as BMI below the $10^{\text {th }}$, between $10^{\text {th }}$ and $90^{\text {th }}$ and above the $90^{\text {th }}$ percentile, respectively.

\section{Biochemical analyses}

Serum was separated by centrifugation and aliquots were stored at $-80^{\circ} \mathrm{C}$ for biochemical analyses. Levels of OC were determined by the fully automated immunoassay system Advantage (Nichols-Diagnostics). The sensitivity of the assay was calculated to be $0.1 \mathrm{ng} / \mathrm{ml}$. Intra- and inter-assay coefficients of variation (CV) were less than $9.5 \%$.

Leptin levels were measured as described previously [10,11]. Adiponectin levels were determined by RIA (Linco Research, Inc., St. Louis, MO). The sensitivity of this assay was calculated to be $1 \mathrm{ng} / \mathrm{ml}$. Intra- and inter-assay CVs were less than 14\%. Resistin levels were determined by an ELISA (Mediagnost, Reutlingen) with a sensitivity of $12 \mathrm{pg} / \mathrm{ml}$ and intra- and inter-assay CVs between $2.4 \%$ and $6.8 \%$.

\section{Statistical analysis}

Some investigated parameters did not adhere to the normal distribution. Comparison of variables was performed using MannWhitney U and Wilcoxon's signed rank test. Spearman's nonparametric correlations was utilized to determine relationships between variables. Multiple stepwise linear regression analysis was performed for OC with age, gender, pubertal stage, BMI standard deviation score (SDS), waist to hip ratio (WHR), fat free mass (FFM), leptin, adiponectin and resistin. Age entered the calculation as squared parameter, because the association of age and OC was non-linear. The selection of variables used for the final regression model was obtained by applying backward elimination to the initial multiple regression model. Repeatedly performing backward elimination and removing the least significant parameter in each step, yielded the removal of (in that order): FFM, WHR, BMI-SDS, adiponectin, resistin, leptin, waist circumference and hip circumference. So the risk for a possible multicolinearity was minimized. The threshold for statistical significance was set at $p<0.05$. Statistical analyses were performed using R (Development Core Team, http://www.R-project. org). The library quantreg version 4.48 by Roger Koenker was used to estimate the age dependent OC centiles as splines with 4 degrees of freedom (http://CRAN.R-project.org/package = quantreg).

If not otherwise mentioned values are given as mean \pm standard deviation.

\section{Results}

$\nabla$

We investigated OC serum levels and different anthropometric parameters in a large and well characterized population of children and adolescents ( $\bullet$ Table 1 ).

In the total study population circulating $O C$ increased during pubertal development reaching highest values in midpuberty (TS3) ( Fig. 1). The peak in the cross-sectional $50^{\text {th }}$ centile of OC occured in girls at 11.9 years and hence earlier than in boys with a peak at 13.2 years. However, the $3^{\text {rd }}$ centile showed no distinct peak at all ( $\bullet$ Fig. 2 ).

OC levels were significantly higher in boys compared to girls if subjects with pubertal stage 1,4 and 5 were compared $(\mathrm{p}<0.05)$. If boys and girls were separately analyzed, all OC levels were significant different in adjacent TS ( $\bullet$ Fig. 1 ) with the exception of the comparison between TS 2 and 3. The resulting centiles for OC in boys and girls depending on age are shown in $\bullet$ Fig. 2 .

This study did not reveal a strong linkage of OC to overweight/ obesity or significantly higher values of OC in lean subjects. Only in early puberty $\mathrm{OC}$ levels were significantly lower in overweight (BMI $>90^{\text {th }}$ percentile) compared to normal weight peers (BMI $10-90^{\text {th }}$ percentile $)(p=0.01)$. If stratified for gender this was only significant for early pubertal boys $(\mathrm{p}=0.01)$ but not for girls ( $\bullet$ Fig. 3). Interestingly, in pubertal stage 3 underweight peers $\left(\mathrm{BMI}<10^{\text {th }}\right.$ percentile) demonstrated significant lower levels of OC if compared to the normal weight group. This was obviously detectable for the mid pubertal combined group of boys and girls $(p=0.03)$ as well as for midpubertal boys alone $(p=0.04)$ but not for girls (data not shown).

WHR, a marker for visceral fat in overweight subjects, showed a positive correlation to serum OC levels in the total study population ( $\mathrm{p}<0.0001, \mathrm{r}=0.202, \mathrm{n}=432$ ). But if stratified for pubertal stage there was only a significant correlation observed between serum OC and WHR in the late pubertal combined group of boys and girls $(\mathrm{p}<0.0001, \mathrm{r}=0.297, \mathrm{n}=172)$ as well as in girls alone $(\mathrm{p}=0.0008, \mathrm{r}=0.358, \mathrm{n}=85)$ but not in boys. As expected, there was a strong relation between WHR and BMI.

The present study demonstrated no significant correlation between serum OC levels and adiponectin or leptin, neither in the total study population nor in the subsets stratified for gender 
Table 1 Anthropometric characteristics of 497 children differentiated by Tanner stage (TS) and gender.

\begin{tabular}{|c|c|c|c|c|c|c|}
\hline & & Age (years) & Height $(\mathrm{cm})$ & Weight (kg) & BMI-SDS & $\mathrm{WHR}^{*}(\mathrm{~cm})$ \\
\hline & & Mean \pm SD & Mean \pm SD & Mean \pm SD & Mean \pm SD & Mean \pm SD \\
\hline \multirow[t]{3}{*}{ total } & $\operatorname{Sum}(n=497 / * 432)$ & $12.33 \pm 2.48$ & $155.40 \pm 14.56$ & $47.55 \pm 13.73$ & $0.16 \pm 1.00$ & $0.80 \pm 0.05$ \\
\hline & Boys $\left(n=247 /{ }^{*} 221\right)$ & $12.77 \pm 2.57$ & $158.99 \pm 15.74$ & $50.27 \pm 14.77$ & $0.12 \pm 1.08$ & $0.82 \pm 0.05$ \\
\hline & Girls $\left(n=250 /{ }^{*} 211\right)$ & $11.90 \pm 2.30$ & $151.86 \pm 12.31$ & $44.87 \pm 12.03$ & $0.20 \pm 0.92$ & $0.78 \pm 0.05$ \\
\hline \multirow[t]{3}{*}{ TS1/2 } & $\operatorname{Sum}\left(n=205 /{ }^{*} 184\right)$ & $10.20 \pm 1.52$ & $143.30 \pm 10.64$ & $37.60 \pm 10.66$ & $0.18 \pm 1.03$ & $0.82 \pm 0.04$ \\
\hline & Boys $\left(n=103 /{ }^{*} 94\right)$ & $10.39 \pm 1.66$ & $144.84 \pm 11.39$ & $39.23 \pm 11.72$ & $0.22 \pm 1.09$ & $0.83 \pm 0.04$ \\
\hline & Girls $\left(n=102 /{ }^{*} 90\right)$ & $10.01 \pm 1.35$ & $141.15 \pm 9.47$ & $35.95 \pm 9.19$ & $0.15 \pm 0.96$ & $0.81 \pm 0.04$ \\
\hline \multirow[t]{3}{*}{ TS3 } & $\operatorname{Sum}\left(n=99 /{ }^{*} 76\right)$ & $12.26 \pm 1.47$ & $157.90 \pm 8.23$ & $49.15 \pm 10.93$ & $0.28 \pm 1.04$ & $0.80 \pm 0.06$ \\
\hline & Boys $\left(n=49 /{ }^{*} 40\right)$ & $13.04 \pm 1.53$ & $161.91 \pm 8.15$ & $53.79 \pm 12.20$ & $0.33 \pm 1.21$ & $0.82 \pm 0.06$ \\
\hline & Girls $\left(n=50 /{ }^{*} 36\right)$ & $11.50 \pm 0.89$ & $153.96 \pm 6.14$ & $44.60 \pm 6.99$ & $0.23 \pm 0.83$ & $0.78 \pm 0.05$ \\
\hline \multirow[t]{3}{*}{ TS4/5 } & $\operatorname{Sum}\left(n=193 /{ }^{*} 172\right)$ & $14.63 \pm 1.45$ & $167.30 \pm 9.12$ & $57.31 \pm 10.09$ & $0.07 \pm 0.95$ & $0.78 \pm 0.05$ \\
\hline & Boys $\left(n=95 /{ }^{*} 87\right)$ & $15.21 \pm 0.91$ & $172.83 \pm 7.52$ & $60.43 \pm 10.00$ & $-0.10 \pm 0.95$ & $0.80 \pm 0.04$ \\
\hline & Girls $\left(n=98 /{ }^{*} 85\right)$ & $14.06 \pm 1.65$ & $161.93 \pm 7.12$ & $54.28 \pm 9.21$ & $0.24 \pm 0.92$ & $0.76 \pm 0.05$ \\
\hline
\end{tabular}

All values presented as mean and standard deviation. TS1/2=prepubertal, TS3= midpubertal, TS4/5=late pubertal. BMI-SDS: body mass index - standard deviation score. WHR: waist to hip ratio. SD: standard deviation. Note in some categories limited information was present, thus the number of study subjects for the WHR was reduced ( $\left.{ }^{*}\right)$

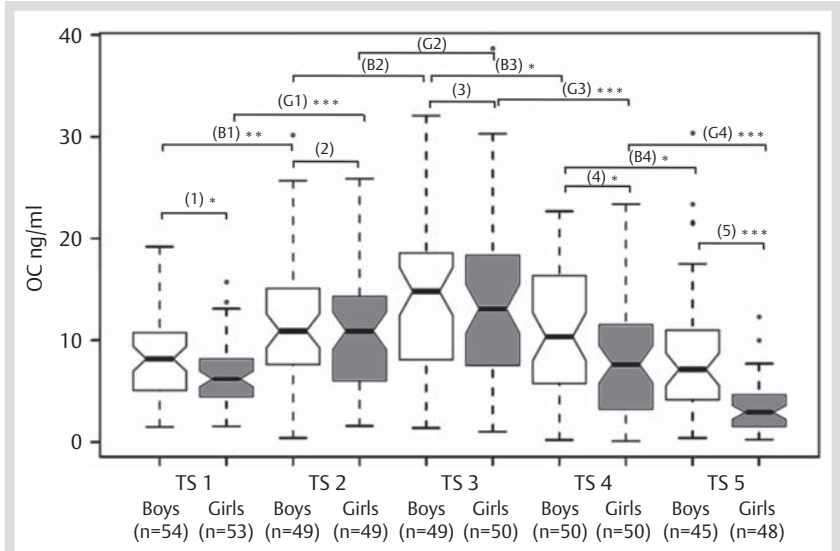

Fig. 1 Osteocalcin serum levels ( $\mathrm{y}$-axis, $\mathrm{ng} / \mathrm{ml}$ ) in boys (white) and girls (grey) depending on Tanner stage (TS). Significance level was set as $p \leq 0.05\left({ }^{*}\right), p \leq 0.01\left({ }^{* *}\right), p \leq 0.001\left({ }^{* * *}\right)$. The effect of gender was compared in each TS ((1) to (5)). OC differences were compared in boys (B1-B4) and girls (G1-G4) for adjacent Tanner stages. The data were analyzed using $\mathrm{U}$-test.

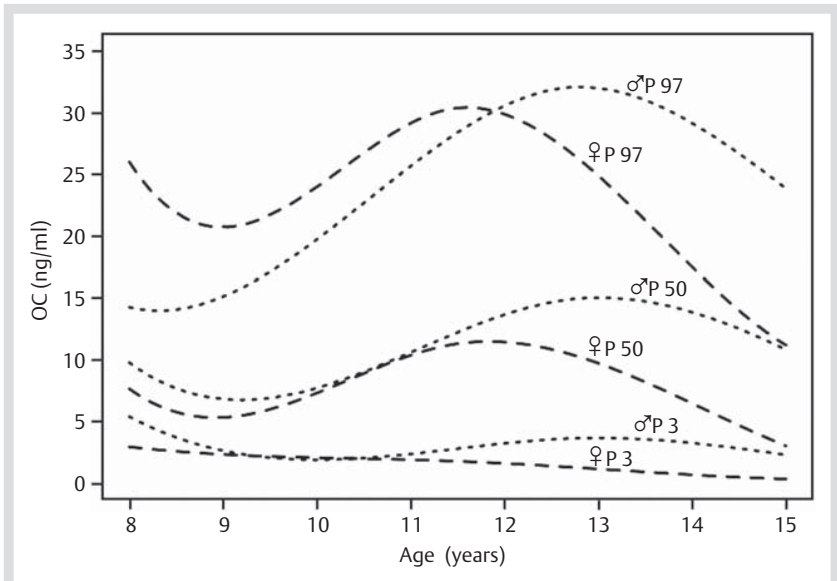

Fig. 2 Centiles for osteocalcin serum levels (p3, p50, p97): depending on age for boys (dotted) and girls (dashed). and BMI. As expected leptin serum levels were elevated in overweight children. Only, in late puberty the combined group of boys and girls showed a significant negative correlation between leptin and OC levels $(\mathrm{p}=0.005, \mathrm{r}=-0.20, \mathrm{n}=193)$.

A significant negative correlation was detectable between OC and resistin serum levels within the total study population $(\mathrm{p}<0.0001, r=-0.330, \mathrm{n}=186)$. This correlation was also significant in each pubertal stage, but if stratified by gender it was only significant in early pubertal boys $(\mathrm{p}=0.008, \mathrm{r}=-0.424, \mathrm{n}=38$ ). The serum levels for OC and measured adipokines were summarized in $\odot$ Table 2 dependent on gender and pubertal stage. Multiple stepwise linear regression analysis of OC with age, gender, pubertal stage, BMI-SDS, waist circumference, hip circumference, WHR, and adipokines revealed only gender, pubertal stage and age as independent predictors ( $\bullet$ Table 3 ). Thereby, age entered the calculation as squared parameter, because the association of age and OC was non-linear. This result was found if the whole study cohort but also if subsets of normal weight peers (BMI $10-90^{\text {th }}$ percentile) and overweight peers (BMI $>90^{\text {th }}$ percentile) were analysed.

\section{Discussion}

\section{$\nabla$}

Our study population demonstrated clearly that OC serum levels were correlated with pubertal development. This correlation is supported by the results of a couple of studies $[12,13]$, whereas other authors did not find such a link $[6,14]$. The detected OC peak levels in TS3 were presumably due to the onset of growth spurt at this pubertal stage. Girls reached the OC peak level at a younger age compared to boys as they enter puberty earlier and onset of growth spurt starts at younger age. OC values were significantly higher in boys compared to girls if subjects with pubertal stage 1, 4 and 5 were compared. For this reason a higher bone mass in boys than in girls could be the explanation [14]. However, there was no major relationship between OC and indicators of body weight, although we can not exclude a minor impact of OC on the very obese phenotype. The significant negative correlation between serum OC levels and indicators of body weight in underweight boys and girls in mid puberty may indicate a later onset of growth spurt in underweight adolescents. Interestingly and opposite to our expectations, girls with increased WHR have higher OC serum levels than girls with nor- 


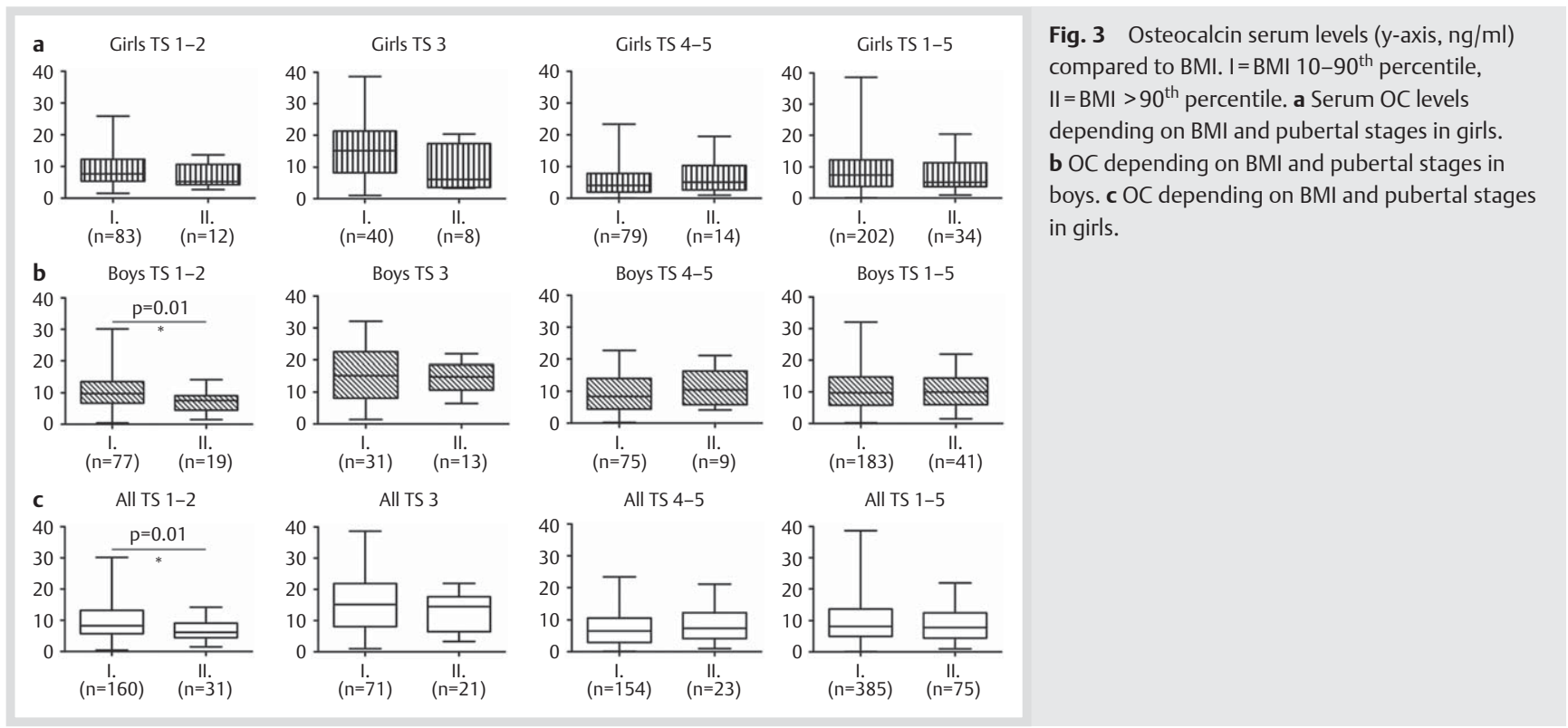

Table 2 Osteocalcin, leptin, resistin and adiponectin serum levels of 497 children, differentiated by Tanner stage (TS).

\begin{tabular}{|c|c|c|c|c|c|}
\hline & & $\begin{array}{l}\text { Osteocalcin }(\mathrm{ng} / \mathrm{ml}) \\
\text { Mean } \pm \text { SD }\end{array}$ & $\begin{array}{l}\text { Leptin }(\mathrm{ng} / \mathrm{ml}) \\
\text { Mean } \pm \text { SD }\end{array}$ & $\begin{array}{l}\text { Resistin* (ng/ml) } \\
\text { Mean } \pm \text { SD }\end{array}$ & $\begin{array}{l}\text { Adiponectin** }(\mathrm{ng} / \mathrm{ml}) \\
\text { Mean } \pm \text { SD }\end{array}$ \\
\hline \multirow[t]{3}{*}{ total } & $\operatorname{Sum}\left(n=497 /{ }^{*} 186 /{ }^{* *} 197\right)$ & $9.78 \pm 6.61$ & $6.67 \pm 5.89$ & $12.77 \pm 6.07$ & $7.02 \pm 2.15$ \\
\hline & Boys $\left(n=247 /{ }^{*} 92 /{ }^{* *} 97\right)$ & $10.86 \pm 6.44$ & $5.05 \pm 5.57$ & $11.59 \pm 6.10$ & $6.73 \pm 2.20$ \\
\hline & Girls $\left(n=250 /{ }^{*} 94 /{ }^{* *} 100\right)$ & $8.72 \pm 6.61$ & $8.29 \pm 5.75$ & $13.92 \pm 5.82$ & $7.30 \pm 2.06$ \\
\hline \multirow[t]{3}{*}{ TS $1 / 2$} & $\operatorname{Sum}\left(n=205 /{ }^{*} 77 /{ }^{* *} 80\right)$ & $9.40 \pm 5.30$ & $6.42 \pm 6.14$ & $12.65 \pm 7.07$ & $7.71 \pm 1.92$ \\
\hline & Boys $\left(n=103 /{ }^{*} 38 /{ }^{* *} 40\right)$ & $9.96 \pm 5.29$ & $6.05 \pm 6.49$ & $11.15 \pm 6.88$ & $7.96 \pm 1.85$ \\
\hline & Girls $\left(n=102 /{ }^{*} 39 /{ }^{* *} 40\right)$ & $8.83 \pm 5.24$ & $6.81 \pm 5.74$ & $14.12 \pm 6.94$ & $7.47 \pm 1.96$ \\
\hline \multirow[t]{3}{*}{ TS 3} & $\operatorname{Sum}\left(n=99 /{ }^{*} 37 / * * 39\right)$ & $14.45 \pm 7.91$ & $7.12 \pm 5.42$ & $11.20 \pm 4.56$ & $6.52 \pm 2.34$ \\
\hline & Boys $\left(n=49 /{ }^{*} 20 /{ }^{* *} 20\right)$ & $14.69 \pm 7.48$ & $6.27 \pm 5.90$ & $10.65 \pm 4.91$ & $5.93 \pm 2.37$ \\
\hline & Girls $\left(n=50 /{ }^{*} 17 /{ }^{* *} 19\right)$ & $14.22 \pm 8.30$ & $7.96 \pm 4.76$ & $11.85 \pm 4.01$ & $7.14 \pm 2.14$ \\
\hline \multirow[t]{3}{*}{ TS 4/5 } & $\operatorname{Sum}\left(n=193 /{ }^{*} 72 /{ }^{* *} 78\right)$ & $7.80 \pm 5.94$ & $6.71 \pm 5.83$ & $13.70 \pm 5.39$ & $6.56 \pm 2.09$ \\
\hline & Boys $\left(n=95 /{ }^{*} 34 / * * 37\right)$ & $9.86 \pm 6.24$ & $3.34 \pm 3.48$ & $12.64 \pm 5.65$ & $5.83 \pm 1.80$ \\
\hline & $\operatorname{Girls}\left(n=98 /{ }^{*} 38 /{ }^{* *} 41\right)$ & $5.80 \pm 4.87$ & $9.97 \pm 5.79$ & $14.65 \pm 4.96$ & $7.22 \pm 2.11$ \\
\hline
\end{tabular}

All values are given as mean and standard deviation. TS1/2=prepubertal, TS3 = midpubertal, TS4/5=late pubertal. Note in some categories limited information was present, thus the number of study subjects for resistin $\left({ }^{*}\right)$ and adiponectin $\left({ }^{* *}\right)$ serum levels was reduced

Table 3 Independent predictors of OC serum levels determined by multiple stepwise linear regression analyses: Pubertal stage and gender were coded as factors. As the relation between OC levels and age was nonlinear, age entered the calculation as squared parameter.

\begin{tabular}{|lclc} 
& B coefficient & standard error & p-value \\
intercept & 9.524 & 0.644 & $<2 \mathrm{e}-16$ \\
\hline TS $1+2$ & 6.579 & 0.859 & $8.00 \mathrm{e}-14$ \\
\hline TS 3 & 10.111 & 0.919 & $<2 \mathrm{e}-16$ \\
\hline TS 4+5 & 4.943 & 1.145 & $1.87 \mathrm{e}-05$ \\
\hline female & -2.544 & 0.501 & $5.20 \mathrm{e}-07$ \\
\hline age (squared) & -0.026 & 0.006 & $7.27 \mathrm{e}-06$ \\
\hline
\end{tabular}

$\mathrm{TS}=$ Tanner stage. $\mathrm{TS} 1+2=$ prepubertal, $\mathrm{TS} 3=$ midpubertal, $\mathrm{TS} 4+5=$ late pubertal

mal WHR. This could be explained by the size of the study subgroups, particularly the low number of obese girls with an increased WHR.

These results are partially in contrast with other studies reporting that obese children had significantly lower OC levels compared with their normal weight peers $[15,16]$. These findings in children was underlined by a recent study showing that substantial weight loss was also associated with an increase in OC
[6]. Most of these studies that demonstrated a clear relation between OC and obesity investigated a larger number of overweight subjects with a broader range in the distribution of fat mass compared to our cohort. The presented cohort included subjects with a rather normal distribution of BMI and so the number of overweight subjects was distinctly lower than in other studies $[6,15,16]$.

As adipokines are indicators of adipose tissue mass, we hypothesized to detect an association between $\mathrm{OC}$ and serum adipokine levels of adiponectin, leptin and resistin [17]. It is well known that obesity and parameters of the metabolic syndrome are associated with high leptin and low adiponectin serum levels [18]. Leptin produced by the adipose tissue could be the link between obesity and low OC serum levels observed in obesity. Moreover, leptin has important effects on bone metabolism [19] and leptin-deficient ob/ob and leptin-resistant mice have elevated OC serum levels [20]. In our study, only in late puberty, the combined group of boys and girls showed a significant negative correlation between leptin and OC levels. Thus, the relation of OC and leptin appears to be dependent on pubertal status.

In rodent models, it was additionally shown, that OC can influence insulin sensitivity and secretion. Thereby, the impact of OC 
on insulin sensitivity and visceral fat mass probably depends on an enhanced expression of adiponectin in adipocytes $[2,4]$. However, in this study no correlation between $\mathrm{OC}$ and adiponectin serum levels was observed.

Resistin initially was studied as a possible link between adiposity and insulin resistance in humans. However, the association between circulating resistin levels and obesity and type 2 diabetes-related phenotypes is unclear [21,22]. Currently, resistin is considered as a marker of inflammation processes related to obesity [23]. From the teleological point of view, low resistin should favor bone growth in the inflammation free status.

This study has a few potential limitations. First, BMI percentiles were used to classify overweight individuals, but BMI is considered to be only one surrogate marker of fat mass. Second, WHR is an acceptable marker for overweight adolescents, but the information in younger individuals is only very limited and somewhat questionable. Unfortunately, the collected data on fat mass, FFM and homeostasis model assessment (HOMA) was insufficient for gender and Tanner stage specific analyses. Third, a cross sectional study of subjects from a community was conducted and the number of overweight or obese subjects was distinctly lower than the number of lean ones. This "mismatch" between obese and normal weight subjects can cause a potential bias in the analysis.

We conclude that there is no major relationship between $\mathrm{OC}$ and metabolism, but we can not exclude minor relations between $\mathrm{OC}$ and metabolism. The negative relationship with serum resistin levels might rather point to a link between OC and inflammatory states. Longitudinal studies are needed for a better understanding of putative interactions between $\mathrm{OC}$ and fat tissue during the transition from normal weight to obesity.

\section{Conflict of Interest: None.}

\section{References}

1 van Summeren $M$, Braam L, Noirt $F$ et al. Pronounced elevation of undercarboxylated osteocalcin in healthy children. Pediatr Res 2007; 61: $366-370$

2 Lee NK, Sowa H, Hinoi E et al. Endocrine regulation of energy metabolism by the skeleton. Cell 2007; 130: 456-469

3 Ducy P, Desbois C, Boyce B et al. Increased bone formation in osteocalcin-deficient mice. Nature 1996; 382: 448-452

4 Ferron $M$, Hinoi $E$, Karsenty $G$ et al. Osteocalcin differentially regulates beta cell and adipocyte gene expression and affects the development of metabolic diseases in wild-type mice. Proc Natl Acad Sci USA 2008; 105: 5266-5270

5 Brandao FR, Vicente EJ, Daltro CH et al. Bone metabolism is linked to disease duration and metabolic control in type 1 diabetes mellitus. Diabetes Res Clin Pract 2007; 78: 334-339
6 Reinehr T, Roth CL. A new link between skeleton, obesity and insulin resistance: relationships between osteocalcin, leptin and insulin resistance in obese children before and after weight loss. Int J Obes (Lond) 2010; 34: 852-858

7 Reich A, Muller G, Gelbrich G et al. Obesity and blood pressure - results from the examination of 2365 schoolchildren in Germany. Int J Obes Relat Metab Disord 2003; 27: 1459-1464

8 Kiess W, Gausche R, Keller A et al. Computer-guided population-based screening system for growth disorders (CrescNet) and on-line generation of normative data for growth and development. Horm Res 2001; 56 (Suppl 1): 59-66

9 Kromeyer-Hauschild $K$, Wabitsch M, Kunze D et al. Percentiles of body mass index in children and adolescents evaluated from different regional German studies. Monatsschrift Kinderheilkunde 2001; 149: 807-818

10 Kratzsch J, Berthold A, Lammert A et al. A rapid, quantitative immunofunctional assay for measuring human leptin. Horm Res 2002; 57: $127-132$

11 Kratzsch J, Lammert A, Bottner A et al. Circulating soluble leptin receptor and free leptin index during childhood, puberty, and adolescence. J Clin Endocrinol Metab 2002; 87: 4587-4594

12 Gundberg CM, Lian JB, Gallop PM. Measurements of gamma-carboxyglutamate and circulating osteocalcin in normal children and adults. Clin Chim Acta 1983; 128: 1-8

13 Yilmaz D, Ersoy B, Bilgin E et al. Bone mineral density in girls and boys at different pubertal stages: relation with gonadal steroids, bone formation markers, and growth parameters. J Bone Miner Metab 2005; 23: $476-482$

14 Hui SL, Dimeglio LA, Longcope C et al. Difference in bone mass between black and white American children: attributable to body build, sex hormone levels, or bone turnover? J Clin Endocrinol Metab 2003; 88: $642-649$

15 Bini V, Igli Baroncelli G, Papi $F$ et al. Relationships of serum leptin levels with biochemical markers of bone turnover and with growth factors in normal weight and overweight children. Horm Res 2004; 61: $170-175$

16 Zamboni G, Soffiati M, Giavarina D et al. Mineral metabolism in obese children. Acta Paediatr Scand 1988; 77: 741-746

17 Koerner A, Kratzsch J, Kiess W. Adipocytokines: leptin - the classical, resistin - the controversical, adiponectin - the promising, and more to come. Best Pract Res Clin Endocrinol Metab 2005; 19: 525-546

18 Bottner A, Kratzsch J, Muller $G$ et al. Gender differences of adiponectin levels develop during the progression of puberty and are related to serum androgen levels. J Clin Endocrinol Metab 2004; 89: 4053-4061

19 Reid IR, Cornish J, Baldock PA. Nutrition-related peptides and bone homeostasis. J Bone Miner Res 2006; 21: 495-500

20 Goldstone AP, Mercer JG, Gunn I et al. Leptin interacts with glucagon-like peptide-1 neurons to reduce food intake and body weight in rodents. FEBS Lett 1997; 415: 134-138

21 Azuma K, Katsukawa F, Oguchi S et al. Correlation between serum resistin level and adiposity in obese individuals. Obes Res 2003; 11: 997-1001

22 Silha JV, Krsek M, Skrha JV et al. Plasma resistin, adiponectin and leptin levels in lean and obese subjects: correlations with insulin resistance. Eur J Endocrinol 2003; 149: 331-335

23 Filkova $M$, Haluzik $M$, Gay $S$ et al. The role of resistin as a regulator of inflammation: Implications for various human pathologies. Clin Immunol 2009; 133: 157-170 